\title{
The crushing weight of urban waste
}

On 20 December 2015, a mountain of construction waste collapsed in Shenzhen, north of Hong Kong. The man-made landslide destroyed 33 buildings, killed 69 people, and left 8 others missing (1). This disaster occurred only 4 months after the chemical explosions in a hazardous material storage facility in Tianjin (2). These events highlight the importance of proper design and risk management during China's rapid urbanization.

Along with unparalleled urbanization, China produced approximately $30 \%$ of the world's municipal solid waste (MSW) in 2012 (3, 4). Construction generates nearly 40\% of China's MSW, more than 200 million tons every year. It also consumes about $40 \%$ of China's natural resources and energy. Rapid urban development is encroaching onto areas previously used for waste disposal that contain toxic substances, endangering human health (5). Landfill areas are filled so rapidly that many cities lack sufficient space to store the waste that is generated. Shenzhen's landfill capacity has been inadequate since early $2015(6)$, but urbanization and the development of a network of underground railway lines continue.

The key solution is the implementation of construction waste minimization at the design stage, as described in the European Commission Waste Framework Directive (7). However, this concept is unknown to more than $60 \%$ of Chinese architects (8). Shenzhen was selected by China's Ministry of Housing and Urban-Rural Development as the pilot city for construction waste minimization and comprehensive utilization in 2012, but this did not stop the landslide tragedy (9). Close monitoring with GPS and other remote sensing techniques of large landfill sites and risk management are also important.

China is not alone. A similar landfill collapse happened in the Philippines' Quezon City, killing at least 278 people (10). These disasters should serve as a turning point for China and other countries to improve construction waste minimization and risk management.

\author{
Hong Yang, ${ }^{1,2 *}$ Xianjin Huang, ${ }^{3} *$ Julian R. Thompson, ${ }^{4}$ Ryan M. Bright,${ }^{1}$ Rasmus Astrup ${ }^{1}$ \\ ${ }^{1}$ Norwegian Institute of Bioeconomy Research (NIBIO), 1431, Ås, Norway. ${ }^{2}$ CEES, Department of Biosciences, \\ University of Oslo, Blindern, 0316, Oslo, Norway. ${ }^{3}$ School of Geographic and Oceanographic Science, Xianlin \\ Campus, Nanjing University, Nanjing, 210023, China. ${ }^{4}$ Department of Geography, University College London, \\ London, WC1E 6BT, UK. \\ *Corresponding author. E-mail: hongyanghy@gmail.com (H.Y.); hxj369@nju.edu.cn (X.H.)

\section{References} \\ 1. China Government. 69 people found dead in Shenzhen landslide (2016); http://www.gov.cn/xinwen/2016-01/13/content 5032448.htm \\ 2. Z. W. Tang, Q. F. Huang, Y. F. Yang, Nature 525, 455 (2015). \\ 3. J. Li, X. Zhong, H. Cai, J. Eng. Manage. 29, 38 (2015). \\ 4. D. Hoornweg, P. Bhada-Tata, "What a waste: a global review of solid waste management," (World Bank, Washington, DC, 2012). \\ 5. H. Yang, X. Huang, J. R. Thompson, R. J. Flower, Science 344, 691 (2014). \\ 6. L. Chen, Shenzhen's 12 landfill storage capacity is full next year (2014); http://wb.sznews.com/html/2014-10/15/content_3030704.htm). \\ 7. European Commission, Construction and Demolition Waste Management Practices and Their Economic Impacts (1999); \\ http://ec.europa.eu/environment/waste/studies/cdw_report.htm. \\ 8. Y. Hao, J. Kang, Building Sci. 26, 4 (2010). \\ 9. J. Wang, X. Kang, V. W. Tam, J. Eng. Des. Tech. 6, 227 (2008). \\ 10. S. M. Merry, E. Kavazanjian Jr, W. U. Fritz, J. Perform. Constr. Facil. 19, 100 (2005).
}

